\section{EMBRYRIDDLE \\ Aeronautical University}

SCHOLARLY COMMONS
International Journal of Aviation, Aeronautics, and Aerospace

\title{
A Looming Pilot Shortage: It is Time to Revisit Regulations
}

Christopher L. Caraway

U.S.Army, carawayc@my.erau.edu

Follow this and additional works at: https://commons.erau.edu/ijaaa

Part of the Benefits and Compensation Commons, Legislation Commons, and the Other Business Commons

\section{Scholarly Commons Citation}

Caraway, C. L. (2020). A Looming Pilot Shortage: It is Time to Revisit Regulations. International Journal of Aviation, Aeronautics, and Aerospace, 7(2). https://doi.org/10.15394/ijaaa.2020.1470

This Position Paper is brought to you for free and open access by the Journals at Scholarly Commons. It has been accepted for inclusion in International Journal of Aviation, Aeronautics, and Aerospace by an authorized administrator of Scholarly Commons. For more information, please contact commons@erau.edu. 
In 2018, Boeing forecasted the demand of 790,000 pilots by 2037 (Coast Flight Training, 2018). This predicted number is a 267\% increase from the 2018 population of active commercial pilots worldwide of 305,000, according to Mazareanu (2018). Kohler (2019) estimates that North America alone will require more than 200,000 new pilots over the next two decades. However, according to student trends monitored by the Federal Aviation Administration (FAA) (2019), the actual number is closer to 360,000 new pilots. The aviation industry will have to double the number of student pilots from the 2018 level and maintain that level for the next 18 years to meet the projected pilot demand. According to the FAA (2019), the number of student pilots was 167,804 in 2018, an 18,863 increase from the 2017 levels. In order to resolve the shortage gap, the aviation community needs to recruit 36,683 new pilots every year from 2018 to 2037. A pilot shortage is looming, and it is time to revisit the regulations.

In the past 106 years, aviation has significantly expanded from a luxury of leisure to a necessity of business and personnel travel. It is the cornerstone for international trade and has been a critical enabler for globalization. Aviation has influenced the current business model in every sector and changed our economic culture. If the aviation industry cannot find a solution to its pilot shortage, then the aviation industry will not be the only economic sector to suffer. The entire global economy will suffer.

This paper will explore business changes airlines need to make to reduce the gap between pilot supply and demand. First, it will look at the history of relevant regulations to determine the intent behind each rule. Next, it will establish other crucial contributing factors to the situation, investigate each rule's ability to meet the intent and the rule's effect on the pilot shortage through complied data, and establish solutions by changing regulations. If the regulations are found not to be a factor, then the paper will evaluate other contributing factors to determine possible solutions to the pilot shortage and suboptimal operations of future aviation operations.

\section{Flight Hour Minimums}

\section{History of Key Aviation Regulations}

In 1997, Congress instructed the FAA to "determine whether current minimum flight time requirements applicable to an individual seeking employment as a pilot with an air carrier were sufficient to ensure public safety" (FAA, 1997, p. 3731). In response, the FAA conducted a study attempting to correlate aviation accidents from 1991 to 1997 with the number of hours pilot-in commands (PIC) and second-in-command pilots (SIC) had at the time of their accident. The FAA's study found the majority of pilots-in-command (53\%) involved in Part 121 accidents had between 10,001 and 20,000 flight hours, and only 7\% of first officers involved in Part 121 accidents had less than 2,000 hours. As a result, the agency 
concluded that there was "no negative relationship between minimum flight hours and National Transportation Safety Board (NTSB) Part 121 and 135 investigated accidents" and recommended no changes to the then 250 flight hour requirement (FAA, 1997, p. 16).

The 250-rule stood in place until 2013 when the FAA aligned the flight hour requirements with the International Civil Aviation Organization's (ICAO) 2011 standard of 1,500 hours for both PICs and SICs with PICs having at least 1,000 hours as a SIC (FAA, 2013; Hoffman, 2014; ICAO, 2011). The FAA contributed this change to Colgan Air 3407 crash in February 2009 (FAA, 2013), but the PIC and SIC of the accident had 3,379 and 2,244 flight hours, respectively (Jansen, 2015). Had the 1500-hour rule been enforced before February 2009, it would not prevent the Colgan Air 3407 crash.

\section{Mandatory Retirement}

When passenger air travel began, there was no regulation forcing pilots to retire at a certain age. In fact, for the first few decades, each airline self-regulated pilot retirements. It was not until 1960 that the FAA created a mandatory retirement of the age 60 for air carrier pilots. When the FAA announced the rule, they gave four reasons behind the rule:

- The process of aging involves "progressive deterioration of certain important physiological and psychological functions";

- the effect of the aging process cannot be determined on an individual basis because each person is affected by the aging process to different degrees at the same point in life;

- degeneration as a result of the aging process occurs at a faster rate the older one becomes; and

- the result of age degeneration is most often sudden incapacity, disabling an individual without prior warnings or symptoms (as cited in Kasperzak Jr., 1981, pp. 244-245).

The given reasons all considered aviation safety; however, the rule formed from ambiguity in the aging process and limitations of the medical field in 1960. As the medical community made medical advancements and poor health habits such as smoking became less acceptable in society, a need for periodic reconsideration of the criteria for a mandatory retirement age of pilots occurred. In 1980, Dr. Stanley Mohler suggested a new standard to determine "pilot fitness: freedom from an impairing disease, the ability to perform, and the desire to continue flying" (Kasperzak Jr., 1981, p. 257). This new criterion did not result in a change in the mandatory retirement age.

In 2004, Dr. Russel B. Rayman redefined the criteria for the mandatory retirement age by asking three questions in a hearing for the Senate's Committee for Aging: "after the age 60, will air transport pilots have a higher aircraft accident rate; will there be significant performance decrement in the cockpit; and will there 
be an unacceptable risk of sudden in-flight incapacitation due to medical causes?" (pp. 1-2). Dr. Rayman was unable to draw a definitive conclusion to the first question because of the 34-year effect of the 60-rule ("A Fresh Look," 2004, p. 2). As for the second and third questions, Dr. Rayman concluded that age had an insignificant impact on decrement in the cockpit, and there were safety precautions in place such as a SIC to prevent accidents in case of incapacitation ("A Fresh Look," 2004, pp. 2-3). Three years later, Congress raised the mandatory retirement age to 65.

\section{Regulatory Effects on the Airline Industry}

Many critics, such as Silk (2017), have contributed pilot shortages to regulations. Some, like Silk (2017), focused on the 1,500 flight hour requirement while others focused on the mandatory retirement age (Kohler, 2019). Each provides substantial arguments to support their claims, but to truly understand these factors, we must conduct a qualitative and quantitative analysis.

\section{The 1,500-Hour Rule}

If the FAA's 1,500-rule is a core cause of the pilot shortage, then we would expect to see a decline in registered airline transport pilots (ATP) and commercial pilots since its enactment in 2013. Instead, since 2013, we see a steady level of combined ATP and commercial pilots with a slight increase in levels in 2017 and 2018. We also see a consistent rise in the number of active ATP certificates since 2013. Commercial pilots are the only area where a significant decline occurs.

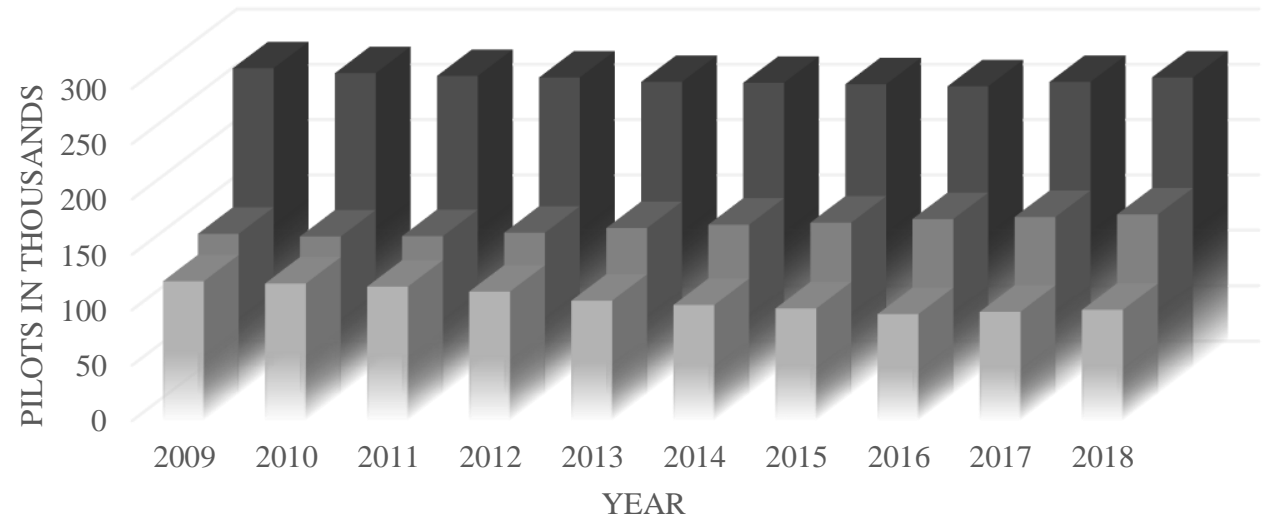

Commercial Pilots $\quad$ Airline Pilots Combined Commercial and Airline Pilots

Figure 1. Active Airmen Certificates (Data compiled from the FAA, 2019). 
Qualitatively, the data does not support the conclusion that the 1,500-rule is contributing to the pilot shortage. Quantitatively, the data infers future issues in the aviation community. First, the rate of growth of ATP and commercial pilots is not significant enough to meet the future demand of 790,000 pilots. Secondly, since current regulations require pilots to obtain a commercial certificate before obtaining an ATP certificate (Office of the Federal Register, 2020) and there is a decline in commercial pilots, current trends suggest the demand for ATPs will deplete the number of commercial pilots until the population of commercial pilots is only pilots older than 65 and pilots with 1,499 hours or less. Once this event occurs, the supply of pilots will force airlines to hire pilots based on availability instead of demand. While data is not available to determine if this event has occurred or when it will occur, incidents such as Horizon Airlines cancellation of 300 flights in June 2017 due to pilot shortages (Smith, 2017) suggests we have reached this critical point of depletion.

Another effect worth consideration is the rule's ability to meet the intent. The FAA enacted the 1,500-hour rule as a response to a fatal crash (FAA, 2013), and Senator Chuch Schumer stated that the regulation "undoubtedly save lives" (as cited in Silk, 2017, para. 25). From this response and statement, the implied intent of the rule is safety. The rule is a safeguard to prevent future accidents. If the rule meets its purpose, we would expect to see a decline in air carrier accidents after July 2013.

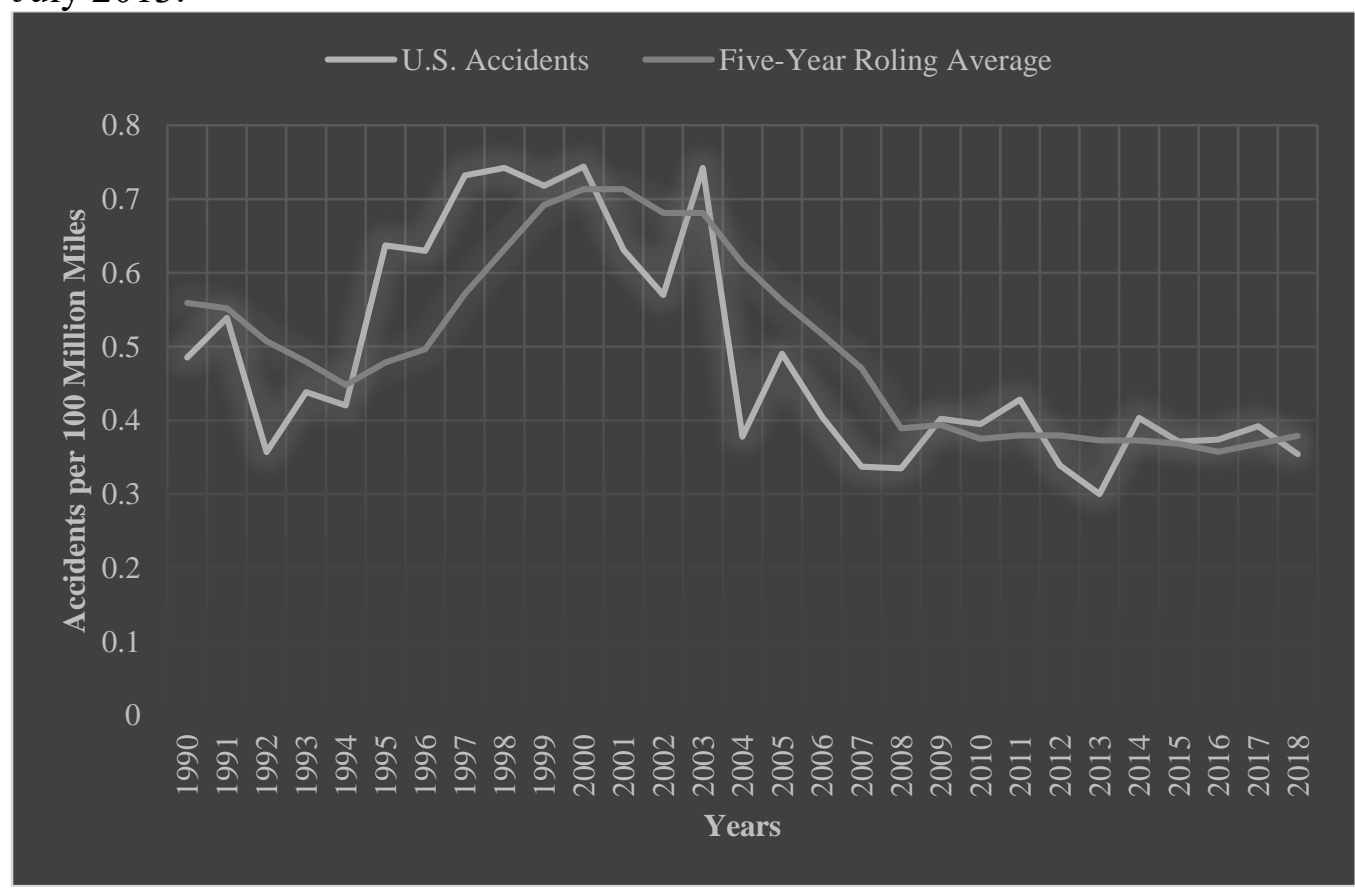

Figure 2. United States Air Carrier Accident Rates 2009 - 2018 (Bureau of Transportation Statistics, 2019). 
When the air carrier accident rate is compared to miles flown, there is a slight decline in the accident rate for three years following 2013; however, the data before 2013 suggests that the 1,500-hour is not the cause of the fall. The sharp decline in the five-year rolling average starting in 2004 indicates there was a change between 2002 and 2003 that resulted in a better safety record. The accident began to stabilize in 2008 , and variations in the accident rate are likely natural fluctuations due to the dynamics of the aviation environment.

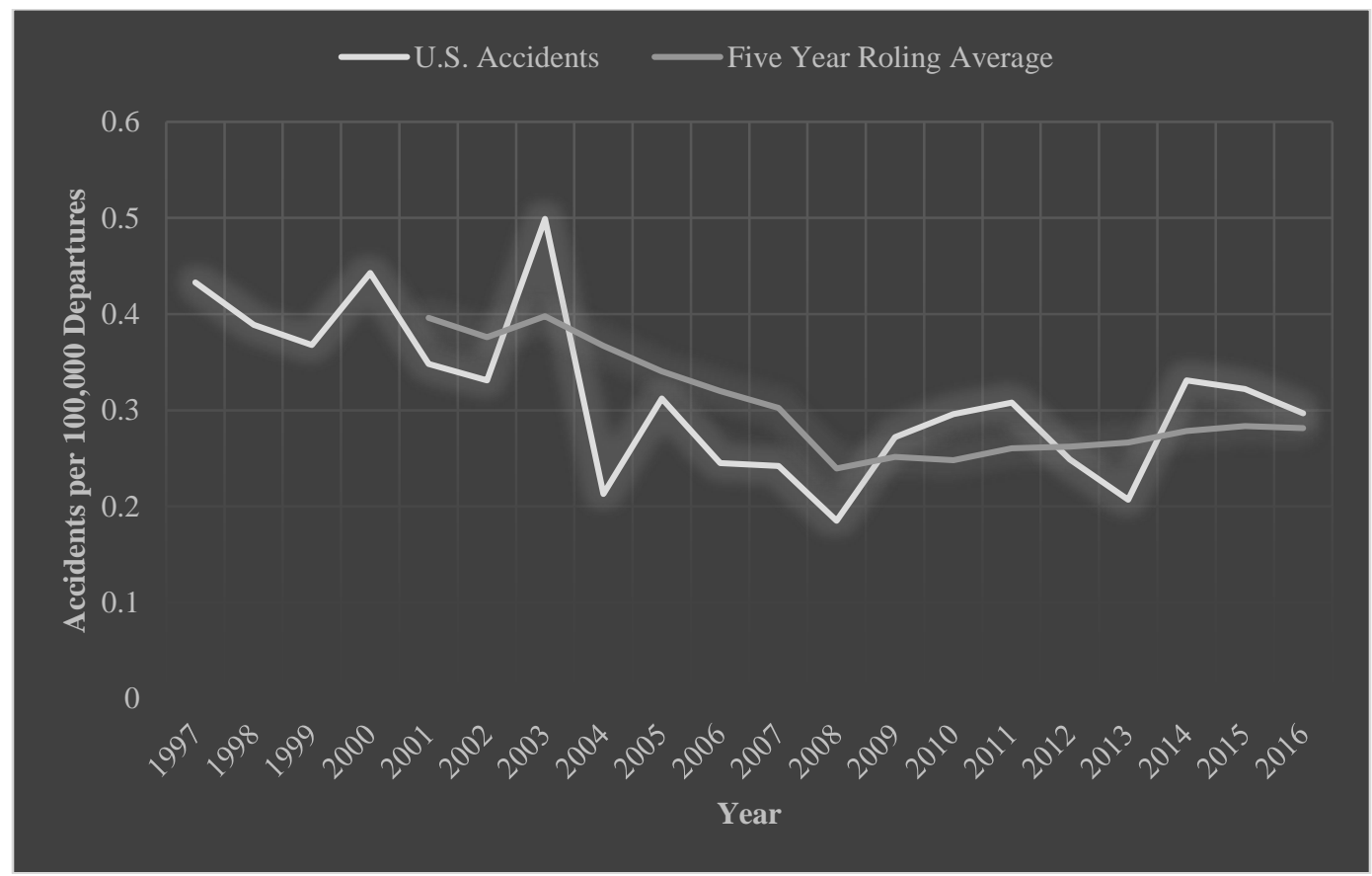

Figure 3. U.S. Airline Accident Rate 1997-2016 According to the NTSB (as cited in Josephs, 2019).

Comparing the accident rate with departures provides a different perceptive to air carriers' safety records. This dataset better depicts the most dangerous modes of flight: take-off and landing. The five-year rolling average supports the same conclusion as the previous dataset. A change caused a significant decline in airline accidents beginning in 2004 and stabilizing in 2008. The slight and steady increase in accident rates after 2008 signals that 1,500-hour rule enacted in 2013 does not affect airline accidents.

\section{Mandatory Retirement}

There are several different estimates on the number of airline pilots retiring in the next decade; however, according to the FAA (2019), 46,188 qualified airline pilots with current medical physicals will lose their ability to fly for an airline in the next eight years. That is an average of 5,773.5 pilots a year. Applying the 
commercial airmen certificate growth for 2018 and assuming that all pilots presently holding commercial pilots qualify for an ATP certificate for the next 20 years, the commercial pilot population will deplete by 2039 if airlines replace all their retiring pilots with commercial pilots. Since the current population of commercial pilots consists of retired airline pilots and pilots that do not have 1,500 yet, the actual date of depletion will occur earlier.

\section{Other Contributing Factors to the Pilot Shortage}

Government regulations have imposed limitations affecting both the entry and exit of the pilot population, but there are other factors limiting entry into the industry. In addition to regulations, Bob Seidel contributes demographic shifts and socioeconomic factors to the pilot shortage (as cited in Garcia, 2018, para. 10). Both factors are worth consideration since demographic shifts in military veterans continuing careers as airline pilots are changing the financial burden most student pilots incur during qualifications.

\section{The Demographic Shift}

According to Kevin Kuhlmann, most pilots hired in the 1980s were from the military, and only a quarter of new pilots were non-veterans, but today that statistic is reverse (as cited in Kohler, 2019, para. 12). The military was a primary and complementary source of pilots in the civilian sector because the military had an abundance of pilots. In 1941, the Army Air Force was producing 30,000 pilots a year due to World War II (Craven \& Cate, 1955, p. 433). Other peaks in pilot training occurred in 1953 as the Air Force produced approximately 7,200 pilots a year for the Korean War and in 1970 with 3,500 annual trainees for the Vietnam War (Ashcroft, 2005; Axe, 2018). After the conclusion of each war, the military reduced the number of pilot positions, and the result was a greater supply of pilots for air carriers than the demand. Regulations would force most of these surplus pilots to retire from the airlines in the 1980s and the last of them to retire in 2019.

Presently, the military is no longer a primary source of pilots for the airlines, nor is it complementary. As of March of 2020, the Air Force had a deficit of 2,100 pilots (Axe, 2020); thus, making the Air Force a competitor for pilots. All branches of the military had similar figures. To gain an advantage in the competition for pilots, the Air Force is introducing several strategies. The Air Force started offering $\$ 420,000$ retention bonuses in 2018 if a pilot completes 12 years in the branch (Losey, 2018). The addition of this bonus means the annual income for an Air Force pilot is between $\$ 74,444$ and $\$ 165,000$ without the inclusion of housing and substance allowances, hazardous flight pay, and additional benefits such as free medical and dental care. The Air Force also offers free flight training and a skill set for a promising career in the airlines after the pilot exits the service. While these strategies are encouraging, the major airlines can still compete with higher pay and the lack of military-related demands; however, there is one strategy the military has 
that can nullify any competition from the airlines. The military, when authorized by the Commander-in-Chief, can involuntarily recall pilots back into service, immediately reducing the number of pilots working for the airlines.

\section{The Socioeconomic Factor}

The demographic shift in pilot backgrounds has resulted in another relevant factor: socioeconomics. When the military was the primary source of pilots for the airlines, the cost of pilot qualification was not a concern for the airlines. The majority of pilots received their qualifications at the expense of the taxpayer. Today, this is no longer true; therefore, pilot qualification costs are now a critical factor in the airlines' ability to recruit new pilots. According to Pletz (2020), it can cost an aspiring pilot $\$ 80,000$ to become a certified pilot instructor (CFI). Embry-Riddle Aeronautical University (2020) estimates that attending flight students will pay between $\$ 91,924$ and $\$ 111,924$ for a four-year aviation degree and a restricted air transport pilot certificate. These costs may discourage aspiring pilots considering the average annual salary for a CFI is $\$ 49,649$ (Glassdoor, 2020), and an entry-level pilot position for a regional airline is approximately $\$ 36,000$ (Epic Flight Academy, 2019).

High pilot qualification costs and low starting salaries place most starting pilots in a financial burden. If a new pilot had accepted $\$ 110,000$ in student loans with an interest rate of $4.79 \%$ for 10 years, then they would be required to pay back $\$ 13,865$ in the first year. Assuming they were also able to obtain a CFI position making $\$ 49,649$, the loan payments would account for $27.9 \%$ of their income. This percentage would increase to $38.5 \%$ if the pilot started working at a regional airline at $\$ 36,000$. After making payments on the student loan, the assumed regional pilot would have a useable income of $\$ 22,134.48$ for their first year, which is below the United States poverty line for a family of four (U.S. Department of Health and Human Services, 2020). Situations like the ones above eliminate potential pilots who cannot afford the qualification costs or do not wish to have a reduced standard of living for the first few years from entering the industry.

\section{Discussion}

The United States government introduced the 1,500-hour rule under favorable intentions. The purpose of the government is to protect the society which it serves. The introduction of the rule in response to a fatal airline crash serves that rationale. Despite the justification for the enactment of the law, insignificant changes in the accident rate after 2013 proves the rule did not meet its intent. If the rule does not meet the designed intention, then we must consider the benefits and liabilities for keeping the rule in its current state.

Several people have claimed the 1,500-hour rule is a cause of the current pilot shortage. The data does not support this claim. The level of commercial and air carrier pilots combined as remained relatively the same since 2009 . The only 
significant change during this period is an increase in air carrier pilots with a corresponding decrease in commercial pilots. If the demand for pilots remained at the 2018 levels, then the argument for revoking the rule would be nugatory. If anything, the rule provides comfort to passengers in the knowledge that their pilots have experience.

Forecasts tell us that the demand for pilots will not remain at the 2018 levels; therefore, keeping the rule in its current state does create liabilities. While the rule does not directly contribute to the pilot shortage, it does limit the rate in which pilots can start working for airlines. Considering the $267 \%$ required increase in pilots by 2037 , the rule may prove detrimental to the airlines' ability to fill flight decks. The airlines would have to deplete the pool of commercial pilots and then wait until future airline pilots obtain 1,500 hours or complete their military obligations. Once the pool of commercial pilots depletes, then a safety issue can arise. An airline's ability to hire quality pilots over minimally qualified pilots is dependent on the number of available applicants. If the number of quality applicants is below the needed amount of pilots, the airlines may feel pressured in hiring pilots having a subpar performance compared to the airline's usual standards, resulting in a compromise in safety. Besides, the rule keeps most starting pilots in positions with low salaries for more prolonged periods; thus, discouraging new pilots from entering the industry.

The government also designed the regulation regarding the mandatory retirement age as a safety consideration. The rationale behind the rule derives from the assumption that pilot skills diminish, and the risk of an incapacitating health event increases with age. In the 1950s and 1960s, limitations in medicine made predicting incapacitating health events difficult. Since pilots required excellent physical and mental health, it was logical for the government to use a general rule of diminishing health rather than individual cases as a measure for retirement.

Today, medical and aviation advancements have changed the dynamics concerning pilot retirements. While not perfect, the medical community can now predict incapacitating health events based on risk factors, key health indicators, and human behaviors. In addition, advancements in technology have enabled more accurate detection of diminishing skills such as sight, reaction time, and cognitive functions. Modern aircraft systems and flight procedures now include precautionary mechanisms that account for an incapacitated pilot. For example, an Airbus a350 is capable of flying based on data entered before the flight and autoland. Also, the flight controls are easily transferable to the alert pilot in the case of an incapacitated pilot. With these advancements and frequent rigorous medical exams, it may be time to considering moving away from a general preventative measure to an individual level.

Still, we must weigh the benefits and liabilities in consideration of the rule's validity. Changing the retirement age would not provide any significant changes to 
the current situation. If the government were to change the age to 67 years old, it would only delay the majority of force retirements by two years in the most favorable circumstances. There is no guarantee that pilots would continue to work past the age of 65 if given the option. Eliminating the retirement age only changes how the government evaluates the competency of pilots. However, the law is still unnecessarily restrictive. Dr. Mohler said that "age alone, as in the case with race or sex, gives no information about an individual's competency or health" (as cited in Kasperzak Jr., 1981, p. 257). Since age alone is not a factor, and we now have measures to protect us from sudden pilot incapacity, the rule no longer serves its purpose and should be eliminated.

Changing either regulation does not provide a significant solution to the pilot shortage. All it will do is remove unnecessary restrictions. Pilot levels did not differ significantly in periods with or without the rules in effect; therefore, we must look at other contributing factors to find a method of recruiting new pilots in the required numbers. Airlines do not have much influence on military manning levels, but they can influence the pilot qualification costs.

The major airlines have an opportunity to eliminate the financial burden for student pilots wishing to become air carrier pilots while making a substantial profit for the airlines. The key to this opportunity is an income share agreement (ISA). In this particular case, an ISA would be a contract between the airline and the student in which the airline pays qualification costs in exchange for a percentage of future wages for a specified period. For example, United Airlines could agree to pay $\$ 110,000$ for a student's degree and flight training in exchange for $6.7 \%$ of the student's future wages for 10 years in which the student is making more than 50,000 dollars, not to exceed $200 \%$ of the cost of training. If executed properly, this method will eliminate the pilot shortage by attracting significantly more aspiring pilots while producing billions of dollars for the airlines.

For the student, ISAs have several advantages over student loans with one notable disadvantage. First, an ISA is not a traditional loan; therefore, it does not go on a student's credit report. As a result, it does not increase the student's debtto-income ratio, allowing the student freedom to make major purchases such as a house. Secondly, the student does not have to worry about the ISA in times of economic hardship. If the student is working below the wage requirement stated in the ISA or became unemployed, then the ISA repayments would be placed on hold. This element of the ISA would significantly reduce the probability of the student living at or below the poverty line. Finally, it allows the student to become financially stable earlier in their life by providing time to establish an emergency fund and other necessary savings. However, there remains the probability that the student would pay more money back to the airlines then if they had elected to use a traditional student loan. Depending on the interest rate, a student may only pay 20,000 dollars in interest with a 110,000-dollar student loan. With an ISA, the 
student could pay between 4,000 and 110,000 dollars in addition to the original 110,000 dollars. However, for the pilot to pay back an additional $\$ 110,000$ with the proposed contracted stated above, the pilot would be making over $\$ 350,000$ in their tenth year.

ISAs also provide several advantages for the airlines. First, the ISA does not take into consideration the employer of the student. If United Airlines paid for the training and the pilot is hired by Delta Airlines, United Airlines still receives a percentage of the pilot's wages. Secondly, it allows the airlines to maintain pilot standards by giving the airlines input into school selection. Airlines can limit ISA offering to students that attend approved schools. Third, if the airline reduces the hourly wage by the percentage stated in the ISA, the airline can reduce the payroll tax owed to the government. Finally, if executed properly, the airlines have the potential to save billions of dollars in wages. If $W_{i}$ equals the wages above the ISA salary requirement a pilot makes in a given year, $I$ equals the interest rate, and $C$ equals qualification costs, then the savings an airline could make is represented by the formulas:

$$
P_{1}=\left(\sum_{i=1}^{10} w_{i}^{*} I\right)-C \text { and } S=\sum_{i=1}^{i=x} P_{i}
$$

where $P$ equals a pilot, and $x$ equals the total number of pilots given ISAs. Given the ISA conditions stated above, the pay scale of United Airline pilots according to Airline Pilot Central (2020a, 202b), and the assumptions that a pilot will not make more than $\$ 50,000$ until they begin employment with a major airline, not change airframes throughout their careers, works 80 hours a month and makes captain at their five-year mark, an airline would expect to save \$4,913.04, 28,931.20, $29,124.16$, and 57,176 for an a319, 757, a320, and 787 pilots respectively. If the airlines give the 360,000 pilots needed to eliminate the pilot gap, then the total savings can range from 1.7 to 20.5 billion dollars. If the airlines were able to capture the maximum repayment of $200 \%$ for all 360,000 pilots, then this number would increase to $\$ 39.6$ billion. However, the airlines will not realize these savings until 12 to 16 years after the investment if the assumption is the pilot works for a regional airline for two years immediately following completion of their flight training. In addition, the airline will assume the risk of ensuring the pilot becomes employed with wages above the ISA requirement.

\section{Conclusion}

Despite several claims, regulations are not the core cause of the current pilot shortage; however, they are unnecessary. They also restrict the rate of growth in the population of commercial and air carrier pilots. Modifying or eliminating these regulations can prove a catalyst to resolve the pilot shortage quickly. Resolving the

pilot shortage issue requires airlines to focus on qualification costs. Improving the 
quality of life and reducing the financial burden of potential pilots should attract the number of pilots needed to meet future demands. Airlines can accomplish this using ISAs. ISAs will not only accomplish the goal of resolving the pilot shortage; it will reduce the student loan crisis and provide an additional benefit of increased profits for the airlines. 


\section{References}

A Fresh Look at Mandatory Retirements: Hearings before the Committee of Aging, Senate, $108^{\text {th }}$ Cong. (2004).

Airline Pilot Central. (2020a, February 10). Skywest. Retrieved from https://www.airlinepilotcentral.com/airlines/regional/skywest

Airline Pilot Central. (2020b, February 12). United Airlines. Retrieved from https://www.airlinepilotcentral.com/airlines/legacy/united_airlines

Ashcroft, B. (2005). We wanted wings: A history of the aviation cadet program. Retrieved from https://media.defense.gov/2015/Sep/11/2001329827/-1/1/0/AFD-150911-028.pdf

Axe, D. (2018, May 4). What's driving the U.S. Air Force pilot shortage?

Retrieved from https://foreignpolicy.com/2018/05/04/whats-driving-the-us-air-force-pilot-shortage/

Axe, D. (2020, March 5). The U.S. Air Force is short thousands of pilots. Retrieved from https://nationalinterest.org/blog/buzz/us-air-force-shortthousands-pilots-2100-be-exact-129657

Bureau of Transportation Statistics. (2019, December 18). U.S. air carrier safety data. Retrieved from https://www.bts.gov/content/us-air-carrier-safetydata

Coast Flight Training. (2018). Boeing forecasts significant pilot shortage at a 10year high. Retrieved from https://iflycoast.com/boeing-2018-pilotshortage-estimate-pushes-demand/

Craven, W. F., \& Cate, J. L. (1955). The Army Air Forces in World War II: Men and planes (Vol. VI). Retrieved from https://www.ibiblio.org/hyperwar/ AAF/VI/AAF-VI-13.html

Embry-Riddle Aeronautical University. (2020). Tution and estimated costs: Fall 2020. Retrieved from https://daytonabeach.erau.edu/admissions/estimatedcosts

Epic Flight Academy. (2019, March 17). How much is an airline pilot's salary. Retrieved from https://epicflightacademy.com/airline-pilot-salary/

Federal Aviation Administration. (1997). Training and qualification issue area. Retrieved from https://www.faa.gov/regulations_policies/rulemaking/ committees/documents/media/TAQacmfT1-01241997.pdf

Federal Aviation Administration. (2013, July 10). FAA boosts aviation safety with new pilot qualification standards. Retrieved from https://www.faa.gov/news/press_releases/news_story.cfm?newsId $=14838$

Federal Aviation Administration. (2019, February 4). U.S. civil airmen statistics. Retrieved from https://www.faa.gov/data_research/aviation data_statistics/civil_airmen_statistics/

Garcia, M. (2018, July 27). A 'perfect storm' pilot shortage threatens global aviation. Retrieved from https://www.forbes.com/sites/marisagarcia/ 
2018/07/27/a-perfect-storm-pilot-shortage-threatens-global-aviation-evenprivate-jets/\#736fb6171549

Glassdoor. (2020, March). Flight instructor salaries. Retrieved from https://www.glassdoor.com/Salaries/flight-instructor-salarySRCH KO0,17.htm

Hoffman, A. (2014, April 22). The effect of the "1,500 hour rule" and new pilot certification and qualification, requirements for air carrier operations. Retrieved from https://www.tmtindustryinsider.com/2014/04/the-effect-ofthe-1500-hour-rule-and-new-pilot-certification-and-qualificationrequirements-for-air-carrier-operations/

International Civil Aviation Organization. (2011, July). Personnel licensing. Retrieved from http://web.shgm.gov.tr/documents/sivilhavacilik/ files/pdf/saglik_birimi/mevzuat/ICAO_Annex\%201-ed11.pdf

Jansen, B. (2015, August 27). Airline fears of pilot shortage spark Congress fight over required training. Retrieved from https://www.usatoday.com/story/ news/2015/08/27/pilot-shortage-faa-1500-hours-required-colgan-crashalpa/32008451/

Josephs, L. (2019, March 8). The last fatal U.S. airline crash was a decade ago. Here's why our skies are safer. Retrieved from https:/www.cnbc.com/ 2019/02/13/colgan-air-crash-10-years-ago-reshaped-us-aviationsafety.html

Kasperzak Jr., R. M. (1981). Mandatory retirement of airline pilots: an analysis of the FAA's age 60 retirement rule. Hastings Law Journal, 33(1), 241-261. Retrieved from https://repository.uchastings.edu/cgi/viewcontent.cgi? article $=2733 \&$ context $=$ hastings_law_journal

Kohler, J. (2019, October 6). Pilot shortage in Colorado and U.S. looms as current flyers are aging out and trainees face steep costs. Retrieved from https://www.denverpost.com/2019/10/06/colorado-pilot-shortage-aviation/

Losey, S. (2018, May 31). Retention bonuses are spiking for a lot of Air Force pilots - could you get up to $\$ 420 K$ ? Retrieved from https://www.airforcetimes.com/news/your-air-force/2018/05/31/retentionbonuses-are-spiking-for-a-lot-of-air-force-pilots-could-you-get-up-to420k/

Mazareanu, E. (2018, August 30). The pilot shortage - statistics \& facts. Retrieved from https:/www.statista.com/topics/4324/the-pilot-shortage/

Office of the Federal Register. (2020, March 24). Electronic code offederal regulations. Retrieved from https:/www.ecfr.gov/cgi-bin/text$\mathrm{idx} ? \& \mathrm{c}=$ ecfr\&tpl=/ecfrbrowse/Title14/14tab_02.tpl

Pletz, J. (2020, February 5). How bad is the pilot shortage? United is buying a flight school. Retrieved from https:/www.chicagobusiness.com/airlinesairports/how-bad-pilot-shortage-united-buying-flight-school 
Silk, R. (2017, August 18). How the 1,500-hour rule created a pilot shortage. Retrieved from https://www.travelweekly.com/Robert-Silk/How-1500hour-rule-created-pilot-shortage

Smith, P. (2017, July 20). The pilot shortage is real and airlines must change before it becomes a full-blown crisis. Retrieved from https://www.businessinsider.com/airline-pilots-reveals-truth-myth-pilotshortage-2017-7

U.S. Department of Health and Human Services. (2020, January 8). Poverty guidelines. Retrieved from https://aspe.hhs.gov/poverty-guidelines 